\title{
Slope Stability Analysis through Integration of Ground Measurements and Remote Sensing Data
}

\author{
Ureel S. D. , Momayez M., Liu Y. \\ Department of Mining and Geological Engineering, University of Arizona, USA
}

Copyright $(\mathrm{C} 2016$ by authors, all rights reserved. Authors agree that this article remains permanently open access under the terms of the Creative Commons Attribution License 4.0 International License

\begin{abstract}
Slope failures and shallow landslides occur due to shallow subsurface flow convergence, soil saturation and shear strength reduction following a heavy rainfall. The semi-arid environment of southern Arizona (AZ) experiences a significant increase in precipitation during the summer. As a result, the soil moisture increases the potential for slope failure due to water table fluctuation and pore pressure escalation. In this paper, the relationship between soil moisture distribution and topography information (slope angle, topography wetness index) is examined using the topography wetness index, NASA's Shuttle Radar Topography Mission (SRTM) images and cokriging. Using the Digital Elevation Model (DEM) generated from remote sensing images, the slope stability analysis is performed in a typical semi-arid environment area using data from the Waternut Gulch Experimental Watershed in Tombstone, AZ. Conclusions and future research are provided at the end of the paper.
\end{abstract}

Keywords Remote Sensing, Slope Stability, Soil Moisture, Cokriging, Wetness Index

\section{Introduction}

Slope stability for soil masses in mining operations and civil engineering projects is a critical issue during watershed and slope water recharge. During this recharge soil moisture and pore pressures may fluctuate and cause instability. In geotechnical engineering, the correlation between soil moisture and pore pressure is used to determine the potential for slope failure. In hydrology, soil moisture is the main parameter used in precipitation-runoff modeling. In a semi-arid environment, massive slopes fail due to run-offs caused by a heavy rain-fall. For example, several debris flows were reported in Sabino Canyon located outside of Tucson, AZ in 2006 after successive rainfall events (Magirl et al., 2007[1]). Ground based measurements of soil moisture are often confined to a limited area because the time and resources to carry out such data collection campaigns are prohibitive. Remote sensing techniques offer a practical alternative for mapping soil moisture over a large area. The Topography Wetness Index (TWI) which can be derived from remote sensing images is widely used to make inferences about the spatial distribution of soil moisture (Lin et al., 2006[2] and Qin et al., 2006[3]). However, the relationship between soil moisture and TWI has yet to be studied in semi-arid environments.

In this paper, the relationship between soil moisture and TWI is examined for a watershed within a semi-arid environment for the very first time. The soil moisture distribution is estimated for the study area using the cokriging technique. Slope stability analysis is carried out using the soil moisture and topography information as input parameters in the model in order to determine the factor of safety of the slope. The results and conclusions are presented in this paper.

\section{Study Area}

Sourthern Arizona has extreme climate conditions with average temperatures ranging from $39^{\circ} \mathrm{C}$ in the summers to $0^{\circ} \mathrm{C}$ in the winter. The study area is centered in the Walnut Gulch Experimental Watershed in Tombstone, AZ (Keefer et al. 2008[4]), encompassing a semi-arid area of 150 square kilometers. The study area has an elevation from $1250 \mathrm{~m}$ to $1580 \mathrm{~m}$ and is covered mostly with shrub and grass. The predominant soil types within the watershed are sandy clay and clay loam. Further information about the study area can be found in Walnut Gulch Brochure, 2007 [5].

Experiments regarding hydrological processes, erosion, sedimentation, and remote sensing have been consistently conducted throughout the past 30 years in and around the study area. The soil moisture profiles used in this research were obtained from rain gauges (Figure 1) installed in the study area. Soil moisture values (\% volumetric water content) from twenty-one stations are measured at different depths $(<5 \mathrm{~cm},<15 \mathrm{~cm}$, etc.). In this paper, the measurements conducted within the top $5 \mathrm{~cm}$ of the soil profile are used since they can be easily detected by both remote sensing and ground measurements. 


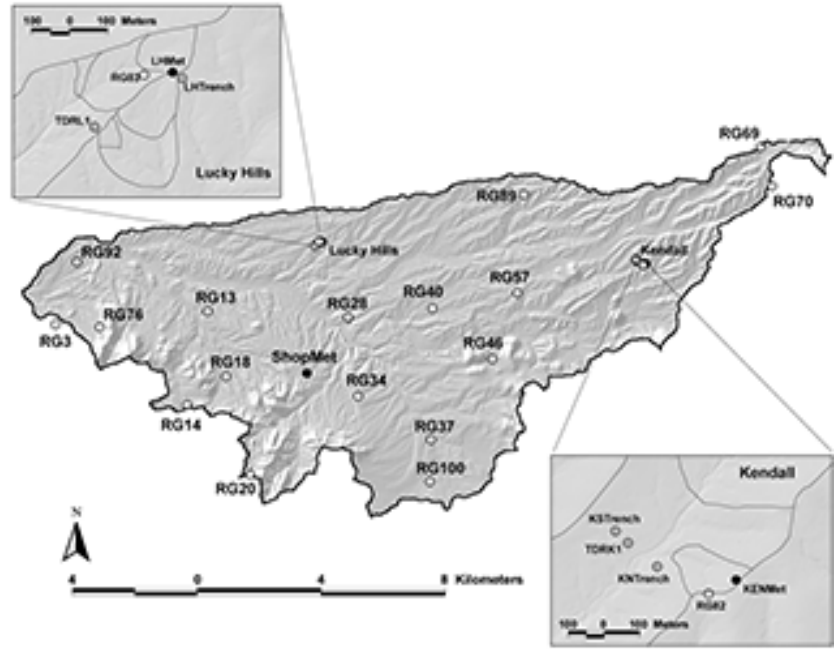

Figure 1. Walnut Gulch Watershed and rain gauges

\section{Data Processing}

The NASA's Shuttle Radar Topography Mission (SRTM) images were acquired for 12 consecutive days beginning February 11, 2000. The extracted sub-image for the study area contains $480 \times 480$ pixels with a resolution of $30 \mathrm{~m}$. The elevation values in the image range from $1159 \mathrm{~m}$ to $2235 \mathrm{~m}$. After generating the DEM, the topography attributes such as slope angle and TWI were calculated. The TWI calculation is based on the 'wetness' index obtained from the TOPMODEL framework (Walter et al., 2002[6]) and the underlying physical process. The index is determined as follows:

$$
T W I=\ln \left(\frac{\alpha}{\tan \beta}\right)
$$

Here $\alpha$ is the specific catchment area (catchment area draining across a unit width of contour), and $\tan (\beta)$ is the local slope of the terrain (Güntner et al., 2004[7]). In order to reduce the amount of voids caused by radar beam's shadow or low backscatter, the original TWI is aggregated for every adjacent 10 by 10 pixels, resulting in a new TWI map at a coarser resolution (1/120 of degree or approximately $1 \mathrm{~km})$ as shown in Figure 3. The aggregation of index values is suggested by SRTM30 documentation from NASA (ftp://e0srp01u.ecs.nasa.gov) which reduces the computation time significantly during the subsequent integration process. Soil moisture data measured on July $29^{\text {th, }} 2003$ are used since there were 2 hours of rain-fall occurring on that day.

The physical value measured at each pixel is often assigned to the pixel's centroid when processing remote sensing images. Thus the coordinates of locations for the soil moisture measurements do also need to be shifted to the centroid of the pixels. Following this step, the linear relationship between soil moisture and the TWI are examined by calculating the correlation coefficient. The value in this case is 0.6 , which indicate a high linear relation when dealing with natural events.

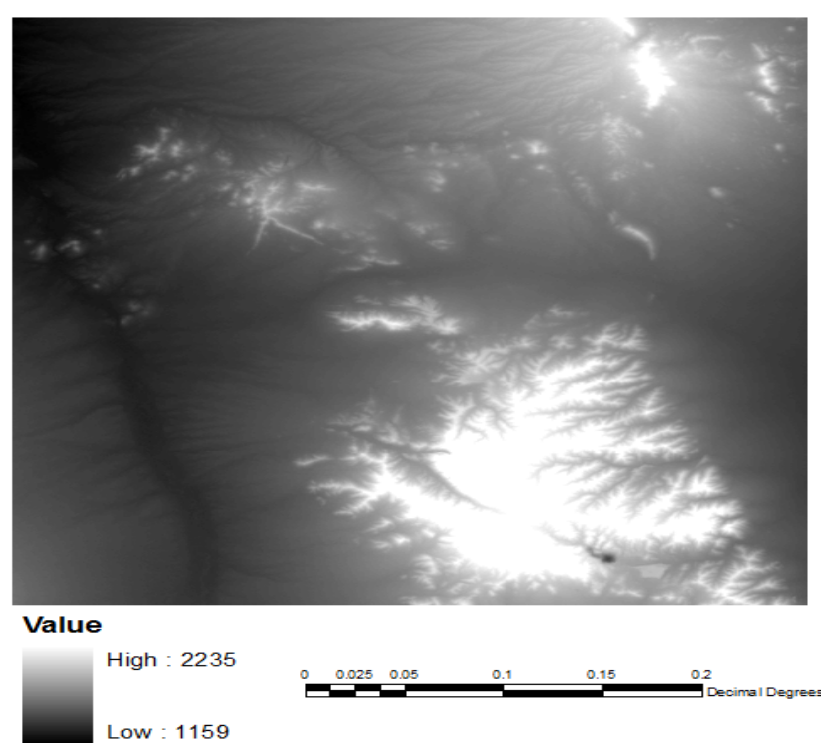

Figure 2. SRTM image for the study area (NASA, 2000)

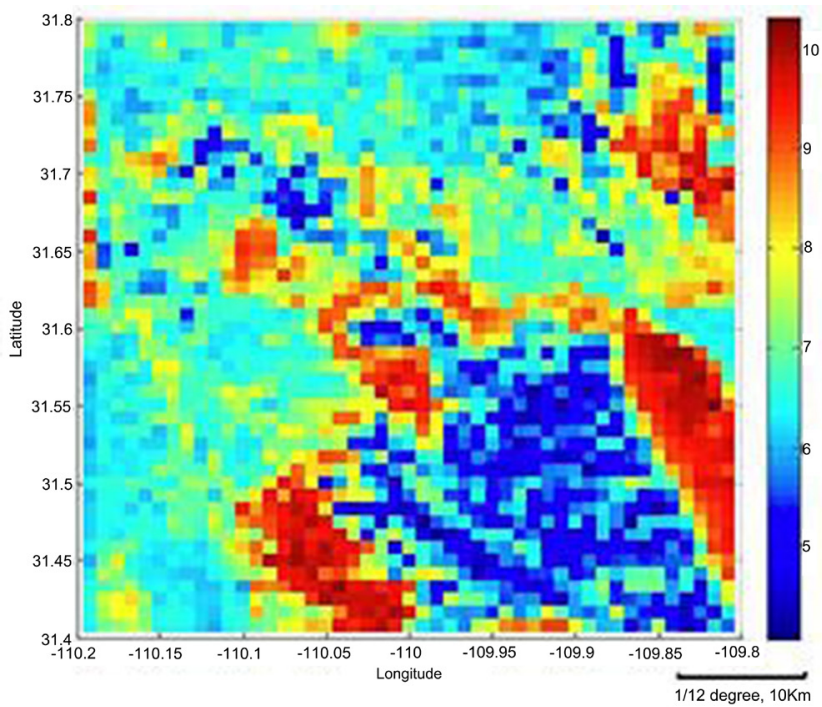

Figure 3. TWI map for the study area

\section{Cokriging}

The number of soil moisture data points on the ground is small compared to the large area of the Walnut Gulch watershed. In order to reduce the uncertainty in the soil moisture distribution and hence the slope stability, the soil moisture values for the entire area are estimated based on the TWI map using cokriging given the linear relationship between TWI and soil moisture. The main idea behind cokriging is to model the variation in the variables under investigation, followed by an estimation of values for locations where no measurements are available. Further information regarding cokringing and geostatistical data for wetness index and remote sensing can be found in Pebesma, 2004[8], Pei et al 2007[9], Boucher and Kyriakidis 2006[10], Trauth, 2006[11]. Figure 4 and 5 show the results of modeling and cokriging. 


\section{Soil Moisture}
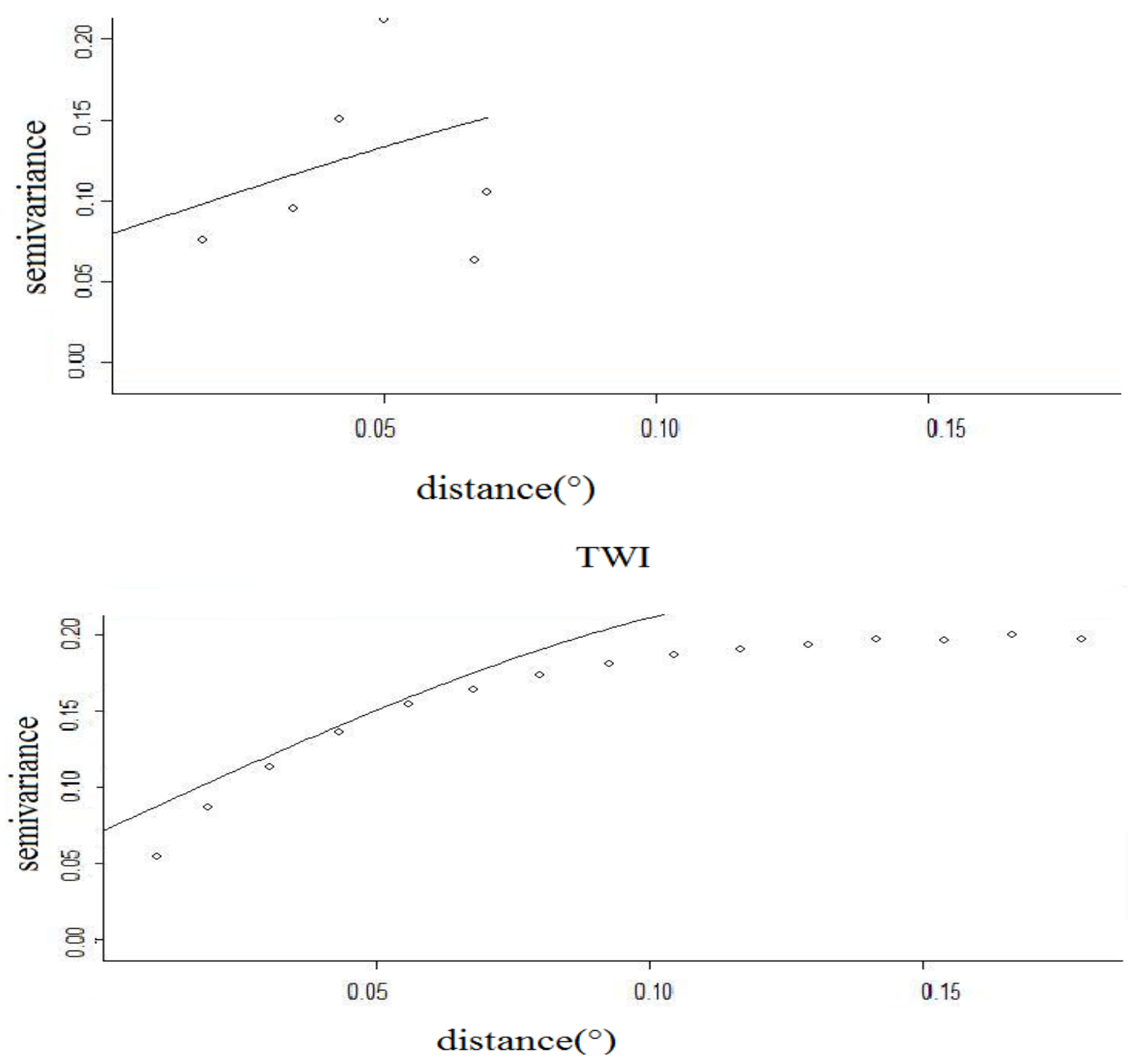

Soil moisture and TWI

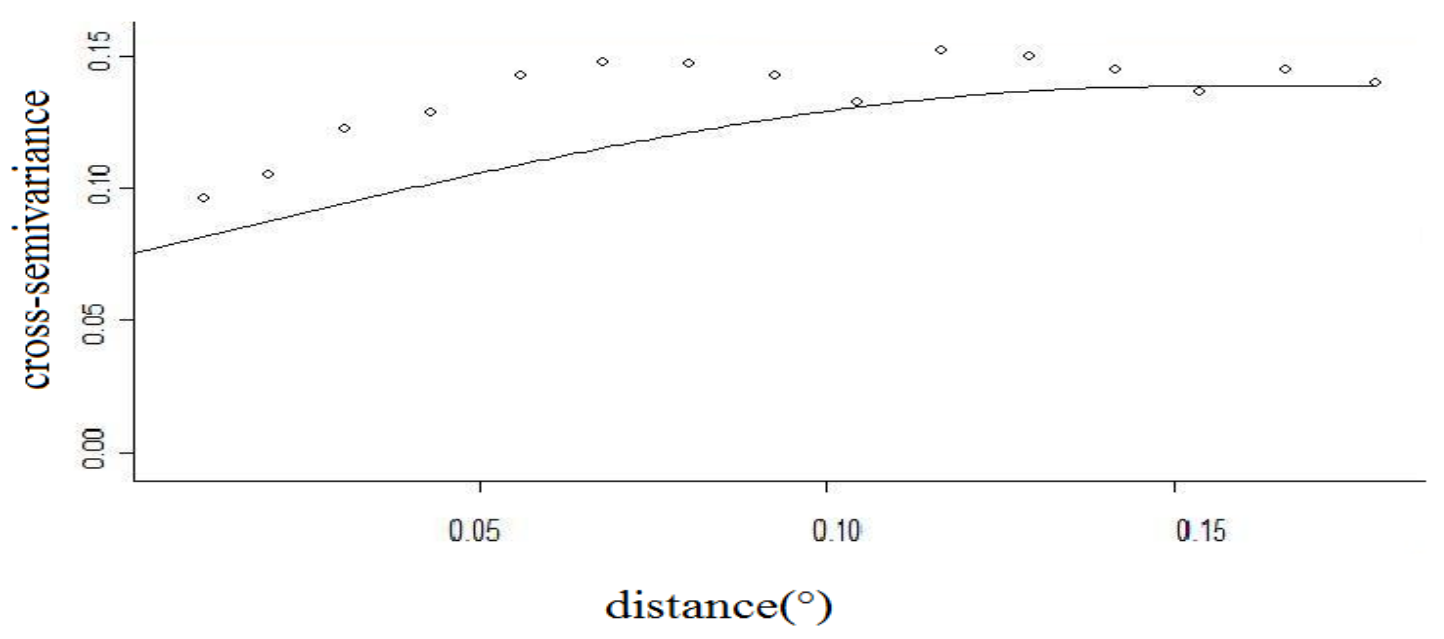

Figure 4. Variation in the variables and modeling (semi-variogram and cross-semi-variogram) 


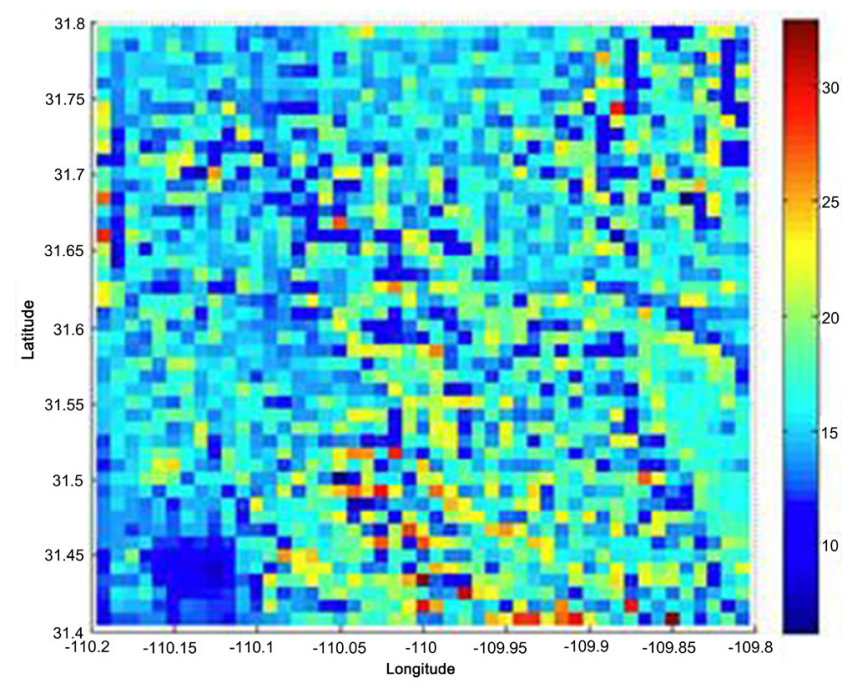

Figure 5. Soil moisture map for the study area

The final soil moisture map presents a large soil moisture variation (from 6 to 30). A visual inspection of the final soil moisture map and the original map reveals that pixels with high moisture content are found around the rim, at an elevation of $1700 \mathrm{~m}$ to $2000 \mathrm{~m}$ or the middle range of the elevations in the study area. The overall error of prediction is $1.2 \%$, which is smaller than the estimate of pure passive microwave measurements obtained by examining the emissivity of soils for the thermal microwave radiation ( $\mathrm{Li}$ and Islam, 1999[12]). Therefore, the uncertainty of soil moisture values is reduced for our further slope stability analysis.

\section{Slope Stability Analysis}

Translational shallow landslides have been found after rain-fall and are considered to be controlled by shallow subsurface flow convergence, soil saturation and shear strength reduction in terms of soil moisture increasing (Vanacker, 2003[13]). These factors are all influenced by surface topography. Hence, in the case of the study area, SINMAP (Pack and Tarboton, 1998[14]) is utilized, since it combines the steady state hydrology assumption with the infinite slope stability model to quantify slope stability and requires the information from soil moisture and topography information. In general, the factor of safety (FS) of a slope is the ratio of the yield load or stress to the working load or stress. Failure occurs when the FS $<1$. The factor of safety (FS) in SINMAP is calculated as:

$$
\mathrm{FS}=\frac{C+\cos \theta\left[1-\min \left(\frac{R a}{T \sin \theta}, 1\right) r\right] \tan \emptyset}{\sin \theta}
$$

Where, $R$ is a steady state recharge $[\mathrm{m} / \mathrm{h}], \mathrm{C}$ is overall cohesion for the soil, $\mathrm{r}$ is water to soil density ratio, $\mathrm{T}$ is the soil transmissivity $\left[\mathrm{m}^{2} / \mathrm{h}\right], \phi$ is the internal friction angle of the soil $\left[{ }^{\circ}\right]$ and $\theta$ is slope angle $\left[^{\circ}\right]$.

The soil moisture parameters $\phi, r$, and $\mathrm{T}$ for the Walnut Gulch study area were obtained by data collected by other researchers. The calculation of FS are then simplified and shown in the Figure 6.

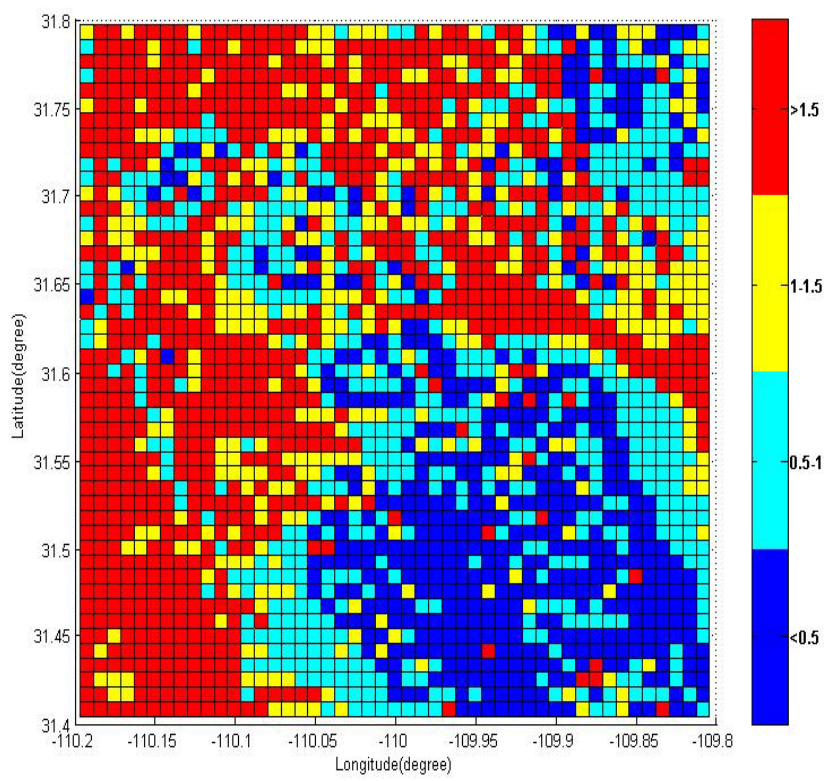

Figure 6. Slope stability index map for the study area

The most unstable areas of the watershed are located in the southeastern part of the study area. By visually examining the slope angle map, the most unstable parts also have steeper angle, ranging from $40^{\circ}$ to $70^{\circ}$. Hence, it is partially indicating that the slope stability is quite influenced by the slope angle. Also, the TWI is very high at the base of the slopes in several locations indicating more water is being collected at the base (toe) of the slope after rain event. This will most likely because higher pore pressures in the toe and provide more driving forces and bring down FS and shear strength of the soil.

\section{Conclusions}

Soil moisture was found to correlate well with topography after rain-fall during the monsoon season in a semi-arid environment. The uncertainty in the soil moisture distribution in a large area could be significantly reduced through integration of single measurements on the ground and remote sensing data. The accuracy of DEM obtained from remote sensing images need to be improved. Remote sensing sources other than STRM (for example LIDAR), could help improve the accuracy and resolution of the DEM. Increasing the number of sites where measurements of soil moisture could be conducted will also improve the accuracy of estimations. The following are recommendations when using remote sensing and slope monitoring systems.

- Increase the size or number of sites to improve accuracy of factor of safety estimation

- Besides soil moisture, remote sensing can be used for other pertinent variables to map factor of safety in an integrated manner

- $\quad$ Resolution of the DEM needs to be improved 
- Slope movement should be modeled as a function of soil properties, slope height and angle, external influences and ultimate failure mechanisms

- Use process-based models to fill gaps in data sets where measurements are limited

- Better slope monitoring techniques and procedures are needed to increase safety and reduce production costs.

In this paper, the authors constructed an integrated slope stability monitoring procedure and provide evidence of its use through remote sensing. Due to the complex interaction between soil, rock and water, the stability of slopes changes as the geological and hydrological conditions change. Better slope monitoring techniques and procedures are needed to increase safety and reduce production costs. Remote sensing techniques provide soil moisture distribution over a larger area and at lower costs than by conventional methods. The advantage of this system is that once the data are analyzed and integrated into spatial and temporal data coverage, inferences regarding ground water flow patterns, soil condition and overall stability of the slope can be made.

\section{Acknowledgements}

The dataset relating to the Walnut Gulch Watershed are provided by U.S. Department of Agriculture, Agricultural Research Service, and Southwest Watershed Research Center (SWRC). The SRTM calculation methods are supported by Jet Propulsion Laboratory from NASA.

\section{REFERENCES}

[1] Magirl, C. S., Shoemaker, C., Webb, R. H., Schaffner, M., Griffiths, P. G. and Pytlak, E., 2007, Debris Flows and Record Floods from Extreme Mesoscale Convective Thunderstorms over the Santa Catalina Mountains, Arizona: U.S. geological survey open file report 2007-1108.

[2] Lin, H. S., Kogelmann, W., Walker, C. and Bruns, M. A., 2006, Soil Moisture Patterns in a Forested Catchment: A Hydropedological perspective, Geoderma 131 (2006) 345-368.

[3] Qin, C., Zhu, A., Yang, L., Li, B., Pei, T., 2006, Topographic
Wetness Index Computed Using Multiple Flow Direction Algorithm and Local Maximum Downslope Gradient, the 7th International Workshop of Geographical Information System

[4] Keefer, T. O., Moran M. S., and Paige, G. B., 2008, Long-term Meteorological and Soil Hydrology Database, Walnut Gulch Experimental Watershed, Arizona, United States, Water Resources Research, Vol. 44, Doi: 10.1029/2006WR005702, 2008

[5] Walnut Gulch Watershed Brochure, 2007, Southwest Watershed Research Center

[6] Walter, M. Todd, Steenhuis, Tammo S., Mehta, Vishal K., Thongs, Dominique, Zion, Mark, and Schneiderman, Elliot, 2002, Refined conceptualization of TOPMODEL for shallow subsurface flows. Hydrological Processes, Vol. 16, No10, pp. 2041-2046.

[7] Güntner, A., Seibert, J., Uhlenbrook, S., Modeling Spatial Patterns of Saturated Areas: An Evaluation of Different Terrain Indices. Water Resour. Res, doi: 10.1029/2003WR002864, 2004

[8] Pebesma, E. J., 2004, Multivariable Geostatistics in S: The Gstat Package, Computers \& Geosciences 30 (2004) 683-691

[9] Pei, T., Qin, C., Zhu, A., Yang, L., Li, B., 2007, Mapping Soil Carbon Using Collocated Cokriging with Wetness Index, 12th Conference of Int. Association for Mathematical Geology

[10] Boucher, A., Kyriakidis, P. C., 2006, Super-resolution Land Cover Mapping with Indicator Geostatistics, Remote Sensing of Environment, Vol.104, Issue 3, Pages 264-282

[11] Trauth, Martin H. 2006, Matlab Recipes for Earth Sciences, New York: Springer.

[12] Li, J., Islam, S, 1999, On the Estimation of Soil Moisture Profile and Surface Fluxes Partitioning from Sequential Assimilation of Surface Layer Soil Moisture, Journal of Hydrology, Vol. 220, Pages 86-103.

[13] Vanacker V., Vanderschaeghe M., Govers G., Willems, E., Poesen, J., Deckers, J., De Bievre, B. 2003. Linking hydrological, infinite slope stability and land-use change models through GIS for assessing the impact of deforestation on slope stability in high Andean watersheds, Geomorphology, Volume 52, Issues 3-4, 16 June 2003, Pages 299-315

[14] Pack, R. T., Tarboton, D. G. and Goodwin, C. N., 1998. The SINMAP approach to terrain stability mapping, Proceedings of 8th Congress of the International Association of Engineering Geology, Vancouver, British Columbia, Canada, pp. $1157-1165$ 